\title{
Low endemism, continued deep-shallow interchanges, and evidence for cosmopolitan distributions in free-living marine nematodes (order Enoplida)
}

Holly M Bik ${ }^{1,2,4^{*}}$, W Kelley Thomas ${ }^{2}$, David H Lunt ${ }^{3}$, P John D Lambshead ${ }^{4}$

\begin{abstract}
Background: Nematodes represent the most abundant benthic metazoa in one of the largest habitats on earth, the deep sea. Characterizing major patterns of biodiversity within this dominant group is a critical step towards understanding evolutionary patterns across this vast ecosystem. The present study has aimed to place deep-sea nematode species into a phylogenetic framework, investigate relationships between shallow water and deep-sea taxa, and elucidate phylogeographic patterns amongst the deep-sea fauna.

Results: Molecular data (18 S and $28 \mathrm{~S}$ rRNA) confirms a high diversity amongst deep-sea Enoplids. There is no evidence for endemic deep-sea lineages in Maximum Likelihood or Bayesian phylogenies, and Enoplids do not cluster according to depth or geographic location. Tree topologies suggest frequent interchanges between deepsea and shallow water habitats, as well as a mixture of early radiations and more recently derived lineages amongst deep-sea taxa. This study also provides convincing evidence of cosmopolitan marine species, recovering a subset of Oncholaimid nematodes with identical gene sequences (18 S, $28 \mathrm{~S}$ and cox 1 ) at trans-Atlantic sample sites.

Conclusions: The complex clade structures recovered within the Enoplida support a high global species richness for marine nematodes, with phylogeographic patterns suggesting the existence of closely related, globally distributed species complexes in the deep sea. True cosmopolitan species may additionally exist within this group, potentially driven by specific life history traits of Enoplids. Although this investigation aimed to intensively sample nematodes from the order Enoplida, specimens were only identified down to genus (at best) and our sampling regime focused on an infinitesimal small fraction of the deep-sea floor. Future nematode studies should incorporate an extended sample set covering a wide depth range (shelf, bathyal, and abyssal sites), utilize additional genetic loci (e.g. mtDNA) that are informative at the species level, and apply high-throughput sequencing methods to fully assay community diversity. Finally, further molecular studies are needed to determine whether phylogeographic patterns observed in Enoplids are common across other ubiquitous marine groups (e.g. Chromadorida, Monhysterida).
\end{abstract}

\section{Background}

The marine environment encompasses nearly $71 \%$ of the earth's surface, with deep-sea habitats (> $400 \mathrm{~m}$ depth) representing $91 \%$ of the total bottom surface area of the world ocean [1]. Given the vastness of this ecosystem, it

\footnotetext{
* Correspondence: h.bik@unh.edu

'Nematode Research Group, Department of Zoology, The Natural History Museum, Cromwell Road, London SW7 5BD, UK

Full list of author information is available at the end of the article
}

is likely that deep-sea fauna constitute a substantial proportion of the Earth's biodiversity; understanding the diversity, abundance, and ecological roles of deep-sea taxa is crucial for quantifying biological contributions to global nutrient cycles such as carbon flux [2]. Assessing the scale of this role is largely dependant on accurately characterizing the abundance and diversity of deep-sea biota, as decreasing biodiversity has been linked to exponential reductions in ecosystem functioning [3].

\section{Biomed Central}

(C) 2010 Bik et al; licensee BioMed Central Ltd. This is an Open Access article distributed under the terms of the Creative Commons Attribution License (http://creativecommons.org/licenses/by/2.0), which permits unrestricted use, distribution, and reproduction in any medium, provided the original work is properly cited. 
Nematodes represent the most abundant metazoan phylum in deep-sea sediments, comprising $85-96 \%$ of all benthic meiofauna [4]. We lack an accurate characterization of species diversity and phylogeographic patterns in this dominant benthic group-a situation hindered by logistical difficulties in sampling the deep-sea and a persistent shortage of nematode taxonomists. Currently, we do not understand what proportion of the deep-sea nematode fauna represents unique taxa (novel species, endemic lineages) and what fraction instead represents a subset of shallow water biodiversity. Fossil evidence $[5,6]$ proposes that deep-sea species originally represented invasions from nearby shallow-water habitats, but 'endemic' lineages developed over time as taxa retreated from shallow water habitats altogether and became strictly deep-sea groups. Evidence from isopods suggests that deep-sea taxa represent a mix of older endemic lineages and fauna derived more recently from shallow water forms. Within the Janiroidea, there is evidence supporting the radiation of shallow-water isopods into deeper habitats through isothermal water columns [7], reinvasions of shallow habitats by deep-sea taxa $[7,8]$, and multiple independent colonizations of the deep-sea [9]-thus, deep-sea taxa within this group probably represent ancient evolutionary lineages that split off early from other taxa [10]. On the other hand, the Flabellifera contains no endemic deep-sea isopod families (in contrast to the Janiroidea which contains seven), and exhibits low diversity in deep habitats [10]; this group is thought to have arisen relatively recently, with shallowwater taxa invading deep-sea habitats subsequent to anoxic oceanic conditions that prompted mass deepwater extinctions in the Palaeocene.

It is unknown whether extant deep-sea nematode species represent relatively recent radiations or older lineages. For small immobile animals such as nematodes, historical expansions and contractions of anoxic zones may have played a large role in shaping phylogeographic patterns amongst taxa [11]. Although nematodes are able to survive low oxygen conditions and short-term anoxia $[12,13]$, they appear unable to survive in permanently anoxic sediments [14]. The scale of past anoxic events is largely unknown, and it is possible that some oxygen minimum zones were patchy and localized rather than globally encompassing the entire deep-sea $[11,15]$; thus, different depths (e.g. abyssal versus bathyal) may have acted variably as source or sink habitats at different timepoints. Many deep-sea genera are cosmopolitan in their occurrence [1], but there is little information on species distributions within this habitat. Limited data from shallow water nematodes indicates that some nematode species have large ranges [16,17], but it is unknown whether or not deep-sea taxa possess similar dispersal capabilities.
Our investigation of deep-sea nematodes has focused on the order Enoplida, a diverse group of species (encompassing many predacious taxa) commonly found in marine sediments. Using up to three gene sequences from individual specimens (18 S rRNA, $28 \mathrm{~S}$ rRNA, and cox1), our narrow taxonomic focus has allowed for an intensive assessment of evolutionary relationships between shallow-water and deep-sea taxa representing multiple ocean basins and a range of collection depths. More concentrated sampling within certain genera has allowed further assessment of geographic patterns within specific deep-sea lineages. By clarifying the phylogenetic placement of deep-sea species, our investigation represents another important step towards a comprehensive molecular framework of the Nematoda. In addition, this study is elucidating biogeographic and bathymetric patterns for the first time using molecular data from deep-sea nematode species; characterizing genetic diversity within this extensive habitat is crucial for quantifying global nematode diversity.

\section{Results}

SSU tree topologies provide substantial insight regarding the evolution of deep-sea species. Phylogenetic relationships amongst Enoplid taxa were overwhelmingly congruent in both Maximum Likelihood and Bayesian tree topologies. Deep-sea nematodes represent a wide taxonomic and phylogenetic breadth within the Enoplida. Deep-sea species were recovered in most marine families-the absence of representatives within some clades may be due to limited sampling. Within genera, phylogenies recovered deep-sea species and shallow water species as sister taxa, as clearly seen for Syringolaimus, Bathylaimus, Oxystomina, Halalaimus, and Chaetonema species (Figure 1); deep-sea taxa do not form an independent lineage within the Enoplida. Within more intensively sampled clades (Figure 2), there does not appear to be any observed clustering pattern according to sample depth or geographic location.

High pairwise sequence identities were observed between many deep-sea and shallow water species, implying a recent divergence between taxa in these habitats. Phylogenetic structures further suggest both frequent and recent interchanges between habitats-there appear to be multiple, independent evolutionary origins for both shallow water and deep-sea taxa. Within the well-sampled genus Halalaimus (Clade IIIa, Figure 1), shallow water lineages appear to have arisen independently at least three times from deep-sea lineages, and there is further evidence for at least three independent invasions of the deep sea. Extant shallow water lineages in Clades IIIb and IIIc (Figure 1) also seem to represent additional derivations from deep-water taxa. Habitat transitions in the opposite direction (shallow to deep) 


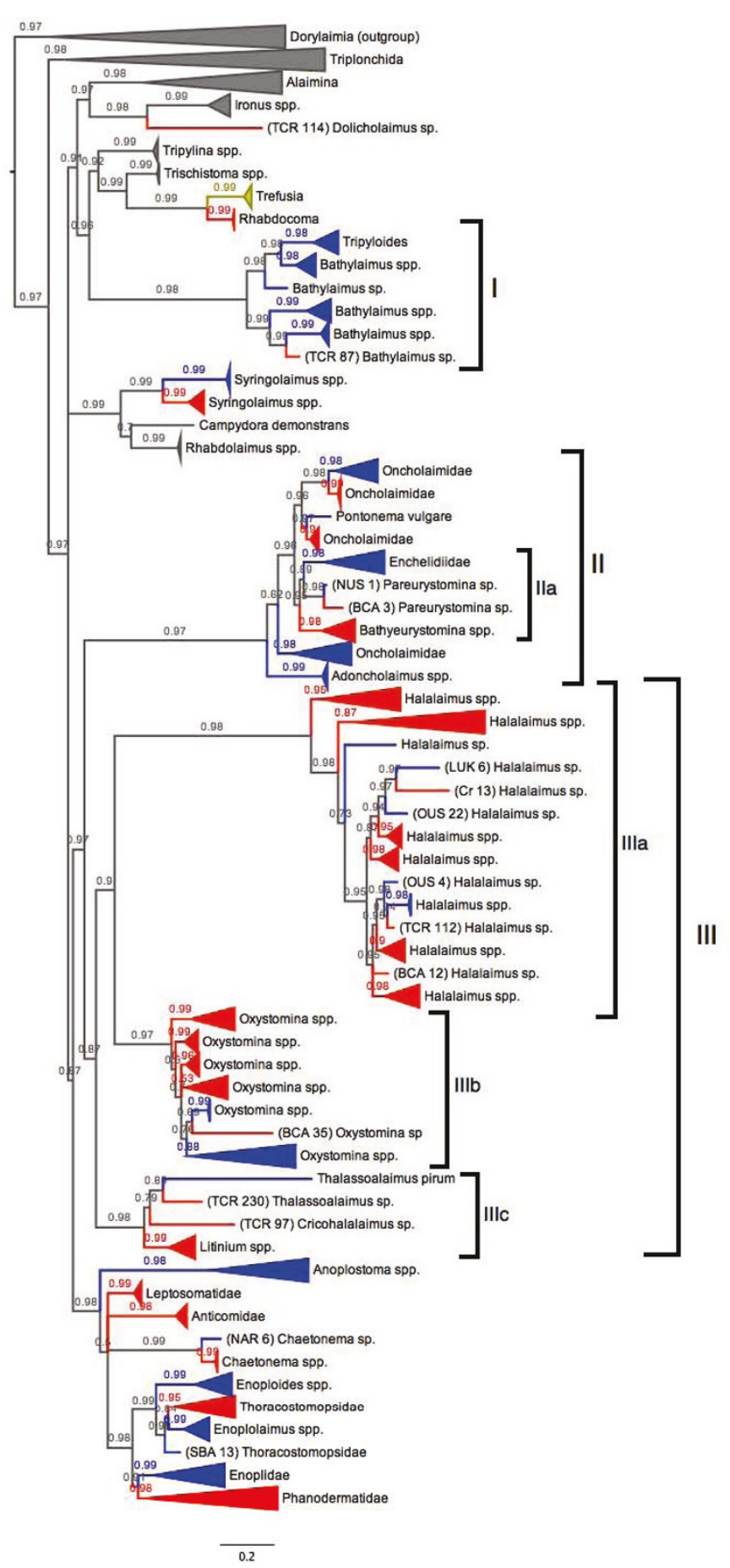

Figure 1 Bayesian phylogeny based on SSU data displaying the habitats of marine nematodes within the Enoplida. Red clades indicate deep-sea species, blue clades represent shallow water species, and yellow clades contain species from both environments.

are instead implied by the structure outlined in Clades I and II (Figure 1); here, deep-sea taxa are recovered as recent splits within primarily shallow clades. The presence of highly divergent, early branching deep-sea lineages within some clades (Clades IIa, IIIa and IIIb,
Figure 1) also suggests a more ancient origin for some groups of deep-sea nematodes.

Sequence data from multiple genes provides some evidence for widespread (and potentially cosmopolitan) distributions in a small fraction of nematode species. 
Pairwise sequence identity comparisons within SSU, LSU, and $\operatorname{cox} 1$ datasets revealed a subset of specimens possessing identical gene sequences. Identical gene sequences were, unsurprisingly, most often observed amongst specimens collected at the same sample site. However, a number of specimens shared identical $18 \mathrm{~S}$ and $28 \mathrm{~S}$ ribosomal sequences (and additionally cox 1 haplotypes) despite being collected from disparate geographic locations (Additional file 1, Table S1). The highest number of identical gene copies were recovered from nematodes belonging to the Oncholaimidae (genera Oncholaimus and Viscosia) collected from intertidal sediments; the distance between sample sites varied from tens to thousands of kilometres (Additional file 1, Table S1). One set of Viscosia specimens were isolated from Devon, England, the Clyde Estuary in Scotland and New Hampshire, USA. Another set of Oncholaimus specimens were collected from at two sites in Massachusetts, USA as well as at two South African beaches. Where available, analysis of mitochondrial sequences showed that nematodes within these two groups additionally shared mitochondrial haplotypes. One group of Oncholaimus specimens with identical ribosomal sequences exhibited two primary mt haplotypes (denoted as B and C in Additional file 1, Table S1); these haplotype sequences only differed by 2 substitutions. Little mitochondrial data was obtained from deep-sea nematodes (due to a low success rate of cox 1 primers), but identical ribosomal sequences were isolated from the Antarctic shelf (Syringolaimus and Oxystomina, Additional file 1, Table S1), bathyal sediments (Thoracostomopsidae and Phanodermatidae, Additional file 1, Table S1), and abyssal habitats (Halalaimus and Chaetonema, Additional file 1, Table S1). Our data further recovered identical gene sequences from Trefusia specimens in the Clyde estuary and Antarctic shelf (Additional file 1, Table S1). Unfortunately, only one specimen was recovered from the Antarcitic shelf site, but this result was surprising given the large distance 
$(\sim 15,000 \mathrm{~km})$ and depth gradient $(670 \mathrm{~m})$ between the two sites.

\section{Discussion}

No endemic deep-sea lineages and frequent deep/shallow interchanges

Prior to this investigation, there were no public data available for reconstructing the evolutionary history of deep-sea nematode taxa. Morphological evidence previously indicated that most deep-sea genera are ubiquitous and benthic community assemblages are similar worldwide [18], although a number of novel deep-sea genera had been identified [19-21]. Within our dataset, deep-sea specimens comprised a taxonomically diverse group of genera representing every major phylogenetic lineage in the Enoplida (Figure 1). Certain genera were particularly abundant in deep-sea sediments (e.g. Halalaimus) and isolated from most geographic locations, supporting previous conclusions from taxonomic studies.

Clade structures (Figure 1) do not reveal any concrete evidence for endemic deep-sea lineages, and deep-sea nematodes do not represent a separate, independent clade within the Nematoda. Instead, specimens are recovered as close relatives of shallow-water species. Our data suggest repeated and recent interchanges between the deep-sea and intertidal zone, supporting ideas that habitat transitions are frequent and common amongst nematodes [22]. A recent study by Van Gaever et al. [23] reported similar findings, observing low shallow-deep molecular divergences in Halomonhystera and Terschellingia specimens inhabiting bathyal shelf sediments. In the present study, topologies of more densely sampled genera provide evidence for multiple, independent invasions of both deep-sea and shallow water habitats. Within the genus Halalaimus (Clade IIIa, Figure 1), there appear to be at least 3 separate invasions of shallow habitats, and evidence for at least 3 independent colonizations of the deep-sea; two deep-sea lineages also appear to show reinvasions from shallow water. Clades I and II (Figure 1) instead support movement from shallow to deep habitats; deep-sea specimens in these clades appear to be recently derived from shallow water fauna.

This complex structure suggests multiple evolutionary origins for deep-sea nematode taxa, similar to patterns observed in isopods [10]. Although we can never unequivocally confirm an exact evolutionary history from phylogenetic topologies, the most parsimonious interpretation of our data supports both deep-sea and shallow water origins for extant Enoplid taxa. In some clades (Clades IIIa and IIIb, Figure 1), extant intertidal taxa may be originally derived from historical source populations in the deep-sea. In other taxa (Clades I and II, Figure 1) deep-sea taxa are instead nested amongst intertidal species, implying recent shallow water ancestry within these clades. Deep-sea clades additionally represent a mixture of early-branching lineages and recently derived taxa (e.g. Clade IIIa, Figure 1), supporting an evolutionary history defined by multiple invasion events. Additional data will continue to add further insight to these emerging patterns; although we aimed for intensive sampling within the Enoplida, our investigation was not an exhaustive inventory of global marine habitats and did not recover all known genera within this group.

Although we cannot label any marine lineage as 'endemic', species distributions of extant nematodes indicate that at least some taxa are not found outside the deepsea. The genus Acantholaimus is rarely found in shallow water, with only one species described from intertidal sediments [24]. Morphological evidence suggests that species within this typical deep-sea group have migrated up to shallower shelf habitats in the Weddell Sea [25]; it is possible that the overall absence of Acantholaimus in shallow habitats could represent a secondary reduction of species in these habitats, following radiation events and speciation in the deep-sea. Although there are currently no molecular studies of Acantholaimus species, the present study has included representatives of another purely deep-sea genus, Bathyeurystomina [26]. This genus does not appear to have any recent shallowwater relatives in molecular phylogenies and appears to have split off early from other genera within the Enchelidiidae (Clade IIa, Figure 1); more extensive sampling is needed to further elucidate generic relationships within this family. Similarly, the genus Cricohalalaimus (Clade IIIc, Figure 1) has only been described from deep-sea sediments [19]- molecular evidence indicates that this taxon represents a divergent lineage that is most closely related to genera Thalassoalaimus and Litinium (SSU and LSU support values >98\%), even though the distinct morphology of Cricohalalaimus does not intuitively suggest a relationship with either group.

\section{Widely distributed, closely related species assemblages in the deep-sea}

Regional isolation in the deep-sea has previously been implied in taxonomic studies, which typically record a high number of distinct, geographically restricted morphospecies and only rare descriptions of the same species from distant locales [1,21]. In our dataset, gene sequences from well-sampled Enoplid clades do not suggest any obvious clustering pattern according to ocean basin or collection depth (Figure 2)-phylogenetic topologies instead indicate widely distributed, closely related species assemblages (with potential conspecific status) in the deep-sea. Many genera contained specimens from distant sample sites that exhibited pairwise sequence identities $>97 \%$. Although such pairwise values are not a 
definitive indicator of a species, these high sequence identities suggest recent vicariance or dispersal between remote deep-sea locations. One set of Phanodermatidae specimens displayed high pairwise identities (99\%) in $18 \mathrm{~S}$ sequences but showed signs of mitochondrial divergence; 'TCR 75' and 'Cr 72b' (Figure 2b) were collected from deep-sea sites 11,000 miles apart and exhibit sequence identities of 99\% (18S), 94\% (28S) and 85\% (cox1). This pairwise identity in cox 1 sequences exceeds interspecific divergence values reported in other nematode genera [ranging from 4.6-13.7\%; 17, [27-29]], suggesting that these two nematodes represent closely related species. Five additional deep-sea Enoplids within the Phanodermatidae exhibited $>99 \%$ SSU sequence identities, but our efforts failed to amplify $\operatorname{cox} 1$ from most of these specimens.

Close phylogenetic relationships were additionally observed amongst specimens from Antarctic shelf habitats (670-1406 m) and abyssal sediments in the Southern Indian Ocean $(\sim 4200 \mathrm{~m})$. Within the Phanodermatidae (Figure 2b), the deep-sea sub-Antarctic specimen ' $\mathrm{Cr}$ 72b' exhibits a 99\% (SSU) and 93\% (LSU) pairwise sequence identity with Antarctic shelf specimen 'BCA 37 ', despite a difference of $\sim 2800$ metres in vertical depths; similar relationships were observed within the genus Halalaimus (Figure 2a). While LSU divergence points towards separate species, high ribosomal sequence identities nonetheless suggest a relatively recent common ancestor between these species. Although we did not sample intermediate depths outside the Southern Ocean, low genetic divergence across vertical depth may be specific to Antarctic shelf habitats; such patterns may reflect historical cycles of shelf ice formation and retreat, where periodic extinctions of shelf fauna were followed by upward migrations of deep-sea taxa [30]. (Apart from identical 18S/28 S sequences observed in Trefusia specimens from the Clyde estuary and the Antarctic shelf, there were no identical sequences representing both deep-sea and shallow water specimens outside the Antarctic.)

A number of benthic species are known to maintain wide geographic distributions in the deep-sea [31,32], although most of these taxa produce dispersive propagule stages or pelagic larvae that facilitate gene flow over these large distances. Marine nematodes lack any obvious propagative phases, and thus little research has been conducted on dispersal mechanisms for deep-sea species. The present study presents compelling evidence for cosmopolitan Oncholaimid species, supporting previous evidence for long-distance dispersal and broad geographic ranges in shallow-water nematodes $[16,17]$. Given the close evolutionary relationships between deep and shallow marine species, it seems plausible that deep-sea species retain behaviours that promote similarly broad distributions in the deep sea. Future investigations will need to sample nematodes from other continental shelf sites in order to assess whether species' large depth ranges are specific to Antarctic habitats.

\section{High nematode diversity in the deep-sea}

Free-living marine nematodes appear to exhibit a high species diversity-a complex branching structure containing a number of divergent clades was observed within the most densely sampled nematode clades, (Clades IIIa and IIIb, Figure 1). Community assemblages in the deep-sea appear to comprise a diverse group of species; specimens representing multiple phylogenetic lineages within the same genus (presumably different species) were often present within the same geographic region, and even within the same sample site. For example, nematodes representing 3 distinct Halalaimus lineages were found within a single sediment core in the Southern Indian Ocean (site 15775\#37, black squares in Figure 2a); at least 8 unique Halalaimus lineages seem to be present across all sites in the Southern Indian Ocean, despite sample areas being no more than $\sim 500$ $\mathrm{km}$ apart (sample codes prefaced with 'Cr' in Figure 2a). Similar patterns were observed in other well-sampled clades such as the Phanodermatidae (Figure 2b) and Oxystomina (Additional file 2, Figure S1).

Although this study aimed to intensively sample Enoplid taxa from each deep-sea site, our overall sampling regime only examined a limited number of sediment cores representing a very small area of the seabed (a total of $785 \mathrm{~cm}^{2}$ ). Our investigation suggests a huge diversity of species, despite this small total surface area. Furthermore, our restricted focus on the order Enoplida analysed only a specific fraction of the diverse nematode assemblages present in deep-sea sediments. Given the diversity uncovered within the Enoplida alone, the global species richness of deep-sea nematode fauna is likely to be very high.

\section{Cosmopolitan species in intertidal habitats}

When added to other evidence of broad species ranges in nematodes $[16,17]$, our results strongly support the existence of cosmopolitan Oncholaimid species. Although several mitochondrial haplotypes were found amongst Oncholaimid specimens possessing identical ribosomal sequences (Additional file 1, Table S1), cox 1 variants only differed at 1-3 nucleotide positions, equating to a genetic divergence $<1 \%$. This low divergence is comparable to intraspecific variation observed in other nematode species [27]; furthermore, the same haplotype was often recovered from transatlantic locations. Potential mechanisms that may help maintain cosmopolitan distributions in Oncholaimids include water-column processes, natural rafts (vegetation masses, sea ice, marine snow) or anthropogenic transport. Hydrodynamic forces have been 
shown to place an important role in the transport of shallow-water meiofauna; heavy storms are known to erode sediments at depths up to $25 \mathrm{~m}$ and carry sediments up to $50 \mathrm{~km}$ away [33], while more typical tidal actions can transport meiofauna at a rate of $10 \mathrm{~km}$ per day as a result of erosion and passive drift [34]. Previous studies have reported an abundance of nematodes in floating mangrove detritus [35], drifting algae [36], and Phaeocystis 'seafoam' [37], promoting the role of raft attachment as a dispersal method. Meiofauna have also been observed to aggregate in clumps of 'marine snow' [38], and transport via these small organic parcels would presumably provide nutritional sustenance during pelagic journeys. Some authors have additionally suggested that meiofauna can be transported via sea ice [33], floating pieces of rubbish [39], or even attached to birds' feet [40]. In terms of anthropogenic transport, ballast water (and its associated sediment) and fouling on vessels are known to carry meiofaunal populations across oceans during shipping operations [33]. The nematode Pellioditis marina is one nematode species that apparently maintains transatlantic populations, and specimens have been found floating in macroalgae rafts in the North Sea [17]; however, the frequency of long-distance dispersal events is unknown.

Behavioural evidence also suggests that Oncholaimids may be particularly adept at long-distance dispersal. Viscosia viscosa often inhabits the surface layers of sediment and is apparently capable of floating [41,42], increasing the probability that this species will be resuspended in the water column and passively transported. In addition, there is evidence to suggest that Oncholaimid nematodes can actively and rapidly transport themselves to suitable new habitats $[41,43,44]$, supplementary to passive mechanisms. Our investigation was focused on a single nematode order that may be unique amongst free-living marine species; many Enoplids are large, predatory nematodes and may thus be more motile than smaller bacterial or fungal feeding nematode species. This motility may enable continued gene flow across geographically disparate sites and prevent allopatric speciation. The unique lifestyles of Enoplid nematodes may also help to explain the closely related species assemblages observed across deep-sea sites. Additional molecular studies are needed in order to assess the distribution of species (and potential for cosmopolitan ranges) in other nematode orders.

Similar patterns may additionally exist within the Trefusiidae; the observation of identical Trefusia species in a Scottish estuary and Antarctic shelf habitats may provide another plausible example of long-distance dispersal as well as eurybathic species distribution, although, only one specimen was recovered from the Antarctic site. Lab contamination can be ruled out, and video capture images of morphology confirm the taxonomic identity of these specimens-regardless, additional data is needed to validate this preliminary insight.

\section{Conclusions}

This study has provided the first insight into the evolution and phylogeography of deep-sea nematode fauna, but much further work is needed. Our data suggest high species richness for marine nematodes, frequent interchanges between deep and shallow habitats, and closely related species complexes in deep-sea habitats, but data from other nematode groups (e.g. Chromadorida, Monhysterida) is needed to assess whether these patterns are broadly applicable to all nematode taxa. Despite the intensive sampling effort of this investigation, deep-sea nematodes were only isolated from a small number of sites representing a minute fraction of the seafloor. In addition, our efforts focused on relationships at the genus level, and the scope of this study was not aimed at delineating species. Future molecular investigations should be expanded to include a wider range of marine sites (shelf, bathyal, and abyssal depths), include a heavy focus on mitochondrial genes (to provide finer resolution at the species level), and represent the full taxonomic spectrum of deep-sea nematode communities.

\section{Methods}

\section{Sample collection}

Samples were collected from several intertidal locations as well as deep-sea sediments (Figure 3); a full list of sampling locations and collection depth is outlined in Additional file 1, Table S2. All marine sediments were immediately fixed in DESS preservative [45] using an equal ratio of preservative to sediment. The meiofauna fraction of all samples was extracted via decantation and

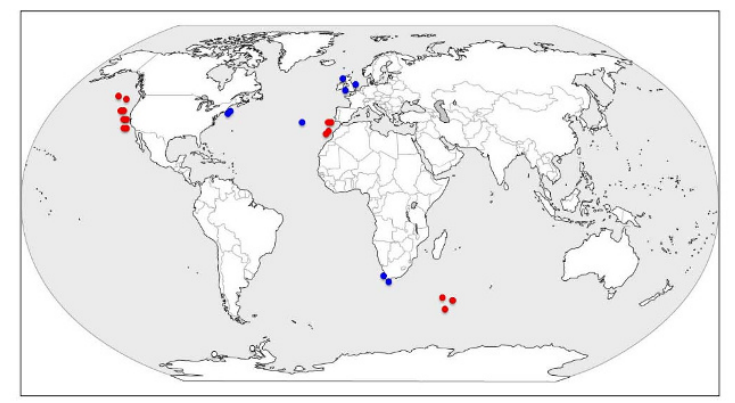

Figure 3 Map outlining sampling locations utilised in this study. Blue dots indicate intertidal sites and red dots indicate deepsea or shelf sites. 
floatation in Ludox using a $45 \mu \mathrm{m}$ sieve according to the methods of Somerfield et al. [46]. Individual nematodes (representing the order Enoplida) were picked out of the meiofauna fraction using a fine wire instrument, mounted on slides, and identified to genus level; video capture images were recorded for all specimens in order to retain a voucher of morphology before specimens were destroyed for molecular analysis. Voucher images were deposited in the NemaTOL database http://nematol.unh.edu/ and are freely available in digital format.

\section{Isolation and sequencing of $18 \mathrm{~S}$ rRNA genes}

Gene sequences were obtained for a total of 254 individual nematode specimens, representing $18 \mathrm{~S}$ rRNA (Accession numbers HM564399-HM564654), 28 S rRNA (Accession numbers HM564655-HM564910), and cox1 (Accession numbers HM564911-HM565012) gene sequences from a variety of Enoplid genera; Morphological IDs and corresponding accession numbers for each nematode specimen are outlined in Additional file 1, Table S3. Genomic DNA was extracted using a proteinase $\mathrm{K}$ digestion [47]; individual specimens were picked into microcentrifuge tubes containing $25 \mu \mathrm{l}$ distilled water, followed by the addition of $25 \mu$ lysis buffer (containing 0.2 M NaCl, 0.2 M Tris- $\mathrm{HCl}$ (pH 8.0), 1\% $\beta$-mercaptoethanol and $800 \mu \mathrm{g} / \mathrm{ml}$ proteinase $\mathrm{K})$. Tubes were incubated for $2 \mathrm{~h}$ at $65^{\circ} \mathrm{C}$ and $750 \mathrm{rpm}$ in an Eppendorf Thermomixer (Eppendorf, Hamburg, Germany), followed by a final $5 \mathrm{~min}$ at $100^{\circ} \mathrm{C}$ and $750 \mathrm{rpm}$. Final lysates were stored at $-20^{\circ} \mathrm{C}$. All PCR reactions were conducted using a DyNAzyme EXT PCR kit (New England Biolabs, Ipswich, MA, USA), with a final reaction volume of $25.75 \mu \mathrm{l}$. Each reaction contained $2 \mu \mathrm{l}$ of nematode genomic DNA, $18.25 \mu \mathrm{l}$ sterile water, $0.4 \mathrm{mM}$ of each primer (Integrated DNA technologies, Coralville, IA, USA) $2.5 \mu \mathrm{l}$ 10X DyNAzyme EXT Buffer containing $\mathrm{MgCl}_{2}$ (final reaction volume $1.5 \mathrm{mM} \mathrm{MgCl}$ ), $0.5 \mu \mathrm{l}$ dNTP mix containing $10 \mu \mathrm{M}$ each nucleotide, and 0.5 $\mu$ l DyNAzyme EXT DNA polymerase (0.5 enzyme units in final reaction volume). Nearly full-length $18 \mathrm{~S}$ rRNA gene sequences $(\sim 1600 \mathrm{bp})$ were amplified from all nematodes using primer sets SSU_F_04 and SSU_R_26, SSU_F_22 and SSU_R_13, and SSU_F_24_1 and SSU_R_81 [48,49] (primer sequences available at http:// www.nematodes.org/research/barcoding/sourhope/ nemoprimers.html). The D2/D3 expansion segment of the $28 \mathrm{~S}$ rRNA gene ( $600 \mathrm{bp})$ was additionally amplified from all specimens using primers D2Ab and D3B [50]. Primers JB3 and JB5 [27] were used to amplify a fragment of the mitochondrial cox 1 gene (393 bp) from a subset of 99 specimens. The following PCR profile was used to amplify all primer sets: $94^{\circ} \mathrm{C}$ for $5 \mathrm{~min}$ followed by 35 cycles of denaturation at $94^{\circ}$ $\mathrm{C}$ for 30 seconds, annealing at $54^{\circ} \mathrm{C}$ for 45 seconds, extension at $72^{\circ} \mathrm{C}$ for 2 minutes, with a final extension of $72^{\circ} \mathrm{C}$ for $10 \mathrm{~min}$. All PCR products were visualized on a $1.5 \%$ agarose gel containing Ethidium Bromide.

Successful PCR reactions were purified using a QIAquick PCR purification kit (QIAGEN, Valencia, CA, USA). Sequencing reactions were carried out using a BigDye Terminator v3.1 cycle sequencing kit (Applied Biosystems, Foster City, CA, USA), with individual sequencing reactions having a final volume of $10 \mu \mathrm{l}$; all PCR products were sequenced in both directions. Each reaction contained $3 \mu \mathrm{l} 5 \mathrm{X}$ ABI sequencing buffer, $2 \mu \mathrm{l}$ of $2 \mu \mathrm{M}$ forward or reverse primer, $1 \mu \mathrm{l}$ BigDye Terminator $\mathrm{v} 1.1$, and either $2 \mu \mathrm{l}$ or $4 \mu \mathrm{l}$ of purified PCR product. Sequencing reactions were carried out using the following thermal profile: $96^{\circ} \mathrm{C}$ for 1 minute followed by 25 cycles of $96^{\circ} \mathrm{C}$ for 10 seconds, $50^{\circ} \mathrm{C}$ for 5 seconds, and $60^{\circ} \mathrm{C}$ for 4 minutes. Cycle-sequence products were purified via ethanol precipitation and sequenced using an ABI 3130 genetic analyzer.

\section{Sequence Alignment and Phylogenetic Analysis}

Pre-aligned structural alignments of $18 \mathrm{~S}$ and $28 \mathrm{~S}$ rRNA genes were downloaded from release 98 of the SILVA rRNA database [51] and imported into the ARB software suite [52]. Enoplid sequences generated during this investigation were incorporated into nematode secondary structure alignments via the Positional Tree (PT) Server function in the ARB software suite. Alignment quality was assessed by first constructing Neighbour-Joining trees in ARB; some manual editing was necessary to ensure that all secondary structure motifs were properly aligned. Short sequences $(<1000 \mathrm{bp})$ and sequences of dubious quality were removed from the alignment. A subset of Dorylaimid nematodes were chosen and aligned as outgroup taxa in ribosomal phylogenies, representing close relatives of the subclass Enoplia [53]. Final $18 \mathrm{~S}$ gene alignments contained contained 354 unique sequences representing 37 genera from the order Enoplida; final LSU datasets contained 280 Enoplid sequences. Sequence from the Rhabditid nematode Pellioditis marina were utilised as outgroup taxa in cox 1 datasets; final mitochondrial alignments contained 105 taxa and were aligned using ClustalW in MEGA 4.0 [54].

Gene alignments were used to construct Maximum Likelihood trees using Randomized Axelerated Maximum Likelihood (RAxML) version 7.04 [55,56], hosted at the Vital-IT unit of the Swiss Institute of Bioinformatics http://phylobench.vital-it.ch/raxml-bb/. Support values were generated from RAxML runs using 100 bootstrap replicates. Bayesian inference was used to supplement topological inferences. Datasets were run for up to 4,000,000 generations using the GTR+I+G model of nucleotide substitution, 4 MCMC chains, and a heating temperature of 0.06 ; in all runs, the first $25 \%$ 
of sampled trees were discarded as burn-in. Data was submitted to the CIPRES project cluster hosted at the University of California, San Diego and analysed using MrBayes3.2 http://www.phylo.org/sub_sections/portal/. In both methods, ribosomal data was analysed using partitions according to secondary structure (Stems/ Loops), while mitochondrial data was run using codon partitions.

\section{Analysis of sequence divergence}

Evolutionary relationships were further investigated by computing pairwise sequence comparisons and analysis of isolation by distance within certain genera. Distance matrices were computed in MEGA v4.0 [54] using p-distances, and pairwise sequence identities were subsequently compared to observed phylogenetic topologies.

\section{Additional material}

Additional file 1: Supplementary tables listing groups of nematodes with identical gene sequences, sample sites utilized in this study, and accession numbers of all gene sequences obtained. Table S1 Groups of Enoplid nematodes exhibiting identical ribosomal sequences. All specimens within each box possess identical copies of both SSU and LSU gene sequences; maximum distance between specimens' collection sites is listed per group. Mitochondrial sequences were additionally isolated from taxa in bold, with letters in brackets representing different cox1 haploypes. Table S2 - Geographic data and collection depth of all sample sites used in this study. Short location codes were used to identify nematodes from different geographic locations after individual specimens were digested for molecular work. Table S3 - Genbank Accession numbers of all $18 \mathrm{~S}, 28 \mathrm{~S}$ and cox 1 sequences amplified during this investigation

Additional file 2: Expanded Bayesian 18 S Phylogeny of the Enoplida. Figure S1 - Bayesian phylogeny based on SSU data displaying the habitats of marine nematodes within the Enoplida, expanded to show all taxa. Black taxa $=$ shallow-water, red taxa $=$ deep-sea Southern Indian Ocean, blue taxa $=$ deep-sea Pacific, and yellow taxa $=$ Antarctic shelf. Collection depths listed after all deep-sea specimens, and sample codes correspond to sample sites outlined in Table 1.

\section{Acknowledgements}

The authors would like to thank David Thistle (NSF grant OCE-0727243), Veerle Huvenne, and Adrian Glover for providing deep-sea sediment cores, Alan Hughes and Lawrence Hawkins for advice and support during this investigation, and Margaret Packer for assisting with sample collection and processing. This work was supported by a Systematics Research Fund Grant (Systematics Association/Linnean Society) to HB and a National Science Foundation award DEB 0228692 to WKT.

\section{Author details}

${ }^{1}$ Nematode Research Group, Department of Zoology, The Natural History Museum, Cromwell Road, London SW7 5BD, UK. ${ }^{2}$ Hubbard Center for Genome Studies, University of New Hampshire, 35 Colovos Road, Durham, $\mathrm{NH}$ 03824, USA. ${ }^{3}$ Department of Biological Sciences, University of Hull, Cottingham Road, Hull HU6 7RX, UK. ${ }^{4}$ School of Ocean and Earth Science, National Oceanography Centre, European Way, Southampton SO14 3ZH, UK.

\section{Authors' contributions}

HMB carried out nematode extraction and sequencing, sequence alignment, tree building, and drafted the manuscript. DHL participated in sequence alignment and tree building. WKT participated in nematode sequencing and aided in designing the study. PJDL conceived the study and participated in its design and coordination. All authors read and approved the final manuscript.

Received: 23 July 2010 Accepted: 18 December 2010

Published: 18 December 2010

\section{References}

1. Miljutin DM, Gad G, Miljutina MM, Mokievsky VO, Fonseca-Genevois V, Esteves AM: The state of knowledge on deep-sea nematode taxonomy: how many valid species are known down there? Marine Biodiversity 2010.

2. Lebrato M, Iglesias-Rodriguez D, Feely RA, Greeley D, Jones DOB, SuarezBosche N, Lampitt RS, Cartes JE, Green DRH, Alker B: Global contribution of echinoderms to the marine carbon cycle: a re-assessment of the oceanic $\mathrm{CaCO}_{3}$ budget and the benthic compartments. Ecological Monographs 2010.

3. Danovaro R, Gambi C, Dell'Anno A, Corinaldesi C, Fraschetti S, Vanreusel A, Vincx M, Gooday AJ: Exponential decline of deep-sea ecosystem functioning linked to benthic biodiversity loss. Current Biology 2008, 18:1-18.

4. Gage JD, Tyler PA: Deep-Sea Biology: A natural history of the organisms at the deep-sea floor Cambridge: Cambridge University Press; 1991.

5. Jablonski D, Bottjer DJ: Onshore-offshore evolutionary patterns in postPaleozoic echinoderms. In Echinoderm Biology, Proceedings of the 6th International Echinoderm Conference. Edited by: Burke RD. Rotterdam: Balkema; 1988:81-90.

6. Sepkoski JJ Jr: A Model of Onshore-Offshore Change in Faunal Diversity. Paleobiology 1991, 17:58-77.

7. Hessler RR, Thistle D: On the place of origin of deep-sea isopods. Marine Biology 1975, 32:155-165.

8. Hessler RR, Wilson GD, Thistle D: The deep-sea isopods: a biogeographic and phylogenetic overview. Sarsia 1979, 64:67-75.

9. Brandt A, De Broyer C, De Mesel I, Ellingsen KE, Gooday AJ, Hilbig B, Linse K, Thomson MRA, Tyler PA: The biodiversity of the deep Southern Ocean benthos. Philosophical Transactions of the Royal Society B 2007, 362:39-66.

10. Wilson GDF: Historical influences on deep-sea isopod diversity in the Atlantic Ocean. Deep-sea Research II 1998, 45:279-301.

11. Rogers AD: The role of the oceanic oxygen minima in generating biodiversity in the deep sea. Deep-Sea Research // 2000, 47:119-148.

12. Cook AA, Lambshead PJD, Hawkins LE, Mitchell N, Levin LA: Nematode abundance at the oxygen minimum zone in the Arabian Sea. Deep-Sea Research I/ 2000, 47:75-85

13. Levin LA, Huggett $C L$, Wishner KF: Controls of deep-sea benthic community structure by oxygen and organic-matter gradients in the eastern Pacific Ocean. Journal of Marine Research 1991, 49:763-800.

14. Danovaro R, Dell'Anno A, Pusceddu A, Gambi C, Heiner I, Mobjerg Kristensen $\mathrm{R}$ : The first metazoa living in permanently anoxic conditions. BMC Biology 2010, 8:30

15. Jacobs DK, Lindbergh DR: Oxygen and evolutionary patterns in the sea: Onshore/offshore trends and recent recruitment of deep-sea faunas. Proceedings of the National Academy of Science USA 1998, 95:9396-9401.

16. Bhadury P, Austen MC, Bilton DT, Lambshead PJD, Rogers AD, Smerdon GR: Evaluation of combined morphological and molecular techniques for marine nematode (Terschellingia spp.) identification. Marine Biology 2008, 154:509-518.

17. Derycke S, Remerie T, Backeljau T, Vierstraete A, Vanfleteren J, Vincx M, Moens T: Phylogeography of the Rhabditis (Pellioditis) marina species complex: evidence for long-distance dispersal, and for range expansions and restricted gene flow in the northeast Atlantic. Molecular Ecology 2008, 17:3306-3322.

18. Vanhove S, Arntz W, Vincx M: Comparative study of the nematode communities on the southeastern Weddel Sea shelf and slope (Antarctica). Marine Ecology Progress Series 1999, 181:237-256.

19. Bussau C: Taxonomische und ökologische untersuchungen an Nematoden des Peru-Beckens. Christian-Albrechts-Universität, Mathematisch-Naturwissenschaftlichen Fakultät; 1993. 
20. Muthumbi A, Soetaert K, Vincx M: Deep-sea nematodes from the Indian Ocean: new and known species of the family Comesomatidae. Hydrobiologia 1997, 346:25-57.

21. Fonseca G, Decraemer W, Vanreusel A: Taxonomy and species distribution of the genus Manganonema Bussau, 1993 (Nematoda: Monhysterida). Cahiers de Biologie Marine 2006, 47:189-203.

22. Holterman $\mathrm{M}$, Holovachov $\mathrm{O}$, Van den Elsen $\mathrm{S}$, van Megen $\mathrm{H}$, Bongers $\mathrm{T}$, Bakker J, Helder J: Small subunit ribosomal DNA-based phylogeny of basal Chromadoria (Nematoda) suggests that transitions from marine to terrestrial habitats (and vice versa) require relatively simple adaptations. Molecular Phylogenetics and Evolution 2008, 48:758-763.

23. Van Gaever S, Olu K, Derycke S, Vanreusel A: Metazoan meiofaunal communities at cold seeps along the Norweigan margin: Influence of habitat heterogeneity and evidence for connection with shallow water habitats. Deep Sea Research Part 1: Oceanographic Research Papers 2009, 56:772-785.

24. Platt HM, Zhang ZN: New species of marine nematodes from Loch Ewe, Scotland. Bulletin of the British Museum of Natural History (Zoology) 1982, 42:227-246.

25. De Mesel I, Lee HJ, Vanhove S, Vincx M, Vanreusel A: Species diversity and distribution within the deep-sea nematode genus Acantholaimus on the continental shelf and slope in Antarctica. Polar Biology 2006, 29:860-871.

26. Lambshead PJD, Platt HM: Bathyeurystomina, a new genus of free-living marine nematodes (Enchelidiidae) from the Rockall Trough. Cahiers de Biologie Marine 1979, 20:371-380.

27. Derycke S, Remerie T, Vierstraete A, Backeljau T, Vanfleteren J, Vincx M, Moens T: Mitochondrial DNA variation and cryptic speciation within the free-living marine nematode Pellioditis marina. Marine Ecology Progress Series 2005, 300:91-103.

28. De Gruijter JM, Polderman AM, Zhu XQ, Gasser RB: Screening for haplotypic variability within Oesophagostomum bifurcum (Nematoda) employing a single-strand conformation polymorphism approach. Molecular and Cellular Probes 2002, 16:185-190.

29. Hu M, Chilton NB, Zhu XQ, Gasser RB: Single-strand conformation polymorphism-based analysis of mitochondrial cytochrome $c$ oxidase subunit 1 reveals significant substructuring in hookworm populations. Electrophoresis 2002, 22:27-34

30. Brey T, Dahm C, Gorny M, Klages M, Stiller M, Arntz WE: Do Antartic benthic invertebrtes show an extended level of eurybathy? Antarctic Science 1996, 8:3-6.

31. Pawlowski J, Fahrni J, Lecroq B, Longet D, Cornelius N, Excoffier L, Cedhagen T, Gooday AJ: Bipolar gene flow in deep-sea benthic foraminifera. Molecular Ecology 2007, 16:4089-4096.

32. Zardus JD, Etter RJ, Chase MR, Rex MA, Boyle EE: Bathymetric and geographic population structure in the pan-Atlantic deep-sea bivalve Deminucula atacellana (Schenck, 1939). Molecular Ecology 2006, 15:639-651.

33. Giere O: Meiobenthology: The microscopic motile fauna of aquataic sediments. 2 edition. Berlin: Springer; 2008.

34. Hagerman GM, Rieger RM: Dispersal of benthic meiofauna by wave and current action in Bogue Sound, North Carolina, USA. Marine Ecology 1981, 2:245-270.

35. Faust MA, Gulledge RA: Associations of microalgae and meiofauna in floating detritus at a mangrove island, Twin Cays, Belize. Journal of Experimental Marine Biology and Ecology 1996, 197:159-175.

36. Arroyo NL, Aarnio K, Bonsdorff E: Drifting algae as a means of recolonizing defaunated sediments in the Baltic Sea. A short-term microcosm study. Hydrobiologia 2006, 554:83-95.

37. Armonies W: Occurrence of meiofauna in Phaeocystis seafoam. Marine Ecology Progress Series 1989, 53:305-309.

38. Shanks AL, Edmondson EW: The vertical flux of metazoans (holoplankton, meiofauana, and larval invertebrates) due to their association with marine snow. Limnology and Oceanography 1990, 35:455-463.

39. Barnes DKA, Milner P: Drifting plastic and its consequences for sessile organism dispersal in the Atlantic Ocean. Marine Biology 2005, 146:815-825

40. Schlichting HE, Speziale BJ, Zink RM: Dispersal of algae and protozoa by Antarctic flying birds. Antarctic Journal of the United States of America 1978, 13:147-149.

41. Da Fonsêca-Genevois V, Somerfield PJ, Baeta Neves MH, Coutinho R, Moens T: Colonization and early succession on artificial hard substrata by meiofauna. Marine Biology 2006, 148:1039-1050.
42. Moens T, Van Gansbeke D, Vincx M: Linking Estuarine nematodes to their suspected food. A case study from the Westerschelde Estuary (southwest Netherlands). Journal of the Marine Biologial Association of the UK 1999, 79:1017-1027.

43. Lorenzen $\mathrm{S}$, Prein $\mathrm{M}$, Valentin C: Mass aggregations of the free-living marine nematode Pontonema vulgare (Oncholaimidae) in organically polluted fjords. Marine Ecology Progress Series 1987, 37:27-34.

44. Prein M: Evidence for a scavenging lifestyle in the free-living nematode Pontonema vulgare. Kieler Meeresforsch 1988, 6:389-394.

45. Yoder M, Tandingan De Ley I, King IW, Mundo-Ocampo M, Mann J, Blaxter M, Poiras L, De Ley P: DESS: a versitile solution for preserving morphology and extractable DNA of nematodes. Nematology 2006, 8:367-376.

46. Somerfield PJ, Warwick RM, Moens M: Meiofauna Techniques. In Methods for the Study of Marine Benthos. 3 edition. Edited by: Eleftheriou A, McIntyre A. Oxford: Blackwell Science; 2005:229-272.

47. Holterman $M$, van der Wurff $A$, van den Elsen $S$, van Megen $H$, Bongers $T$, Holovachov O, Bakker J, Helder J: Phylum-wide analysis of SSU rDNA reveals deep phylogenetic relationships among nematodes and accelerated evolution toward crown clades. Molecular Biology and Evolution 2006, 23:1792-1800.

48. Blaxter ML, De Ley P, Garey JR, Liu LX, Scheldeman P, Vierstraete A, Vanfleteren JR, Mackey L, Dorris M, Frisse LM, Vida JT, Thomas WK: A molecular evolutionary framework for the phylum Nematoda. Nature 1998, 392:71-75.

49. Meldal BHM, Debenham NJ, De Ley P, Tandingan De Ley I, Vanfleteren JR, Vierstraete AR, Bert W, Borgonie G, Moens T, Tyler P, Austen MC, Blaxter M, Rogers AD, Lambshead PJD: An improved molecular phylogeny of the Nematoda with special emphasis on marine taxa. Molecular Phylogentics and Evolution 2007, 42:622-636.

50. De Ley P, Félix MA, Frisse LM, Nadler SA, Sternberg PW, Thomas WK: Molecular and morphological characterisation of two reproductively isolated species with mirror-image anatomy (Nematoda: Cephalobidae). Nematology 1999, 1:591-612.

51. Pruesse E, Quast C, Knittel K, Fuchs BM, Ludwig W, Peplies J, Glöckner FO: SILVA: a comprehensive online resource for quality checked and aligned ribosomal RNA sequence data compatible with ARB. Nucleic Acids Research 2007, 35:7188-7196.

52. Ludwig W, Strunk O, Westram R, Richter L, Meier H, Kumar Y, Buchner A, Lai T, Steppi S, Jobb G, Förster W, Brettske I, Gerber S, Ginhart AW, Gross O, Grumann S, Hermann S, Jost R, König A, Liss T, Lüßmann R, May M, Nonhoff B, Reichel B, Strehlow R, Stamatakis A, Stuckmann N, Vilbig A, Lenke $M$, Ludwig T, et al: ARB: a software environment for sequence data. Nucleic Acids Research 2004, 32:1363-1371.

53. Van Megen $H$, Van den Elsen $S$, Holterman $M$, Karssen G, Mooyman $P$, Bongers T, Holovachov O, Bakker J, Helder J: A phylogenetic tree of nematodes based on about 1200 full-length small subunit ribosomal DNA sequences. Nematology 2009, 11:927-950.

54. Tamura K, Dudley J, Nei M, Kumar S: MEGA4: Molecular Evolutionary Genetics Analysis (MEGA) software version 4.0. Molecular Biology and Evolution 2007, 24:1596-1599.

55. Stamatakis A: RAxML-VI-HPC: Maximum Likelihood-based phylogenetic analyses with thousands of taxa and mixed models. Bioinformatics 2006, 22:2688-2690

56. Stamatakis A, Hoover P, Rougemont J: A rapid bootstrapping algorithm for the RAxML web-servers. Systematic Biology 2008, 75:758-771.

doi:10.1186/1471-2148-10-389

Cite this article as: Bik et al: Low endemism, continued deep-shallow interchanges, and evidence for cosmopolitan distributions in free-living marine nematodes (order Enoplida). BMC Evolutionary Biology 2010 10:389. 